\title{
Extra intestinal influences on exhaled breath hydrogen measurements during the investigation of gastrointestinal disease
}

\author{
D G THOMPSON, P BINFIELD, A DE BELDER, J O'BRIEN, S WARREN, \\ AND M WILSON
}

From the Departments of Gastroenterology and Physiology, the London Hospital Medical College, Whitechapel, London

SUMMARY During the clinical investigation of patients with gastrointestinal disease by exhaled breath hydrogen measurement, the occurrence of inexplicable variations in recorded hydrogen values led to a search for extra intestinal factors which were capable of adversely influencing breath hydrogen concentration and impairing the diagnostic accuracy of the test. Serial breath samples were collected from normal subjects under a variety of conditions which might occur during routine clinical study, including, hyperventilation, exercise, cigarette smoking, and carbohydrate ingestion. Breath hydrogen concentrations were consistently reduced by hyperventilation $(p<0.01)$ and exercise $(p<0.05)$. Cigarette smoking, in contrast, caused a marked rise in measured breath hydrogen $(\mathrm{p}<0.01)$, as did oral carbohydrate $(\mathrm{p}<0.05)$. Prior bactericidal mouthwash abolished this carbohydrate associated rise, suggesting that the hydrogen was the result of fermentation by oropharyngeal bacteria. Because, in all instances, the changes in breath hydrogen were of sufficient magnitude to interfere with data interpretation, it is recommended that these factors are eliminated, whenever possible, from conditions of study.

The passage of unabsorbed dietary carbohydrate into the caecum is followed in most individuals by the production of hydrogen, a metabolic consequence of carbohydrate fermentation by anaerobic bacteria. ${ }^{1}$ This hydrogen traverses the gut wall, and is transported via the circulation to the lungs, where it is excreted, in exhaled breath. Thus, in normal subjects, after ingestion of an incompletely absorbed carbohydrate, serial measurements of exhaled breath hydrogen concentration begin to show a rise after its arrival at the caecum, and provide a simple index of orocaecal transit.

Since the realisation of the clinical value of this phenomenon, ${ }^{2}$ its applications have steadily grown and now include the investigation of carbohydrate malabsorption, ${ }^{34}$ upper intestinal bacterial overgrowth, ${ }^{5}$ and abnormal upper intestinal transit. ${ }^{6}$

Inexpensive apparatus for breath hydrogen measurement using an electrochemical cell ${ }^{7}$ (GMI Ltd, Renfrew, Scotland) has recently been developed and has greatly simplified the technique and made it

\footnotetext{
Address for correspondence: Dr D G Thompson, Medical Unit, The London Hospital. London E1 1BB.

Received for publication 22 February 1985
}

available for clinical use in any district hospital.

As with other techniques, however, exhaled breath hydrogen monitoring has proved to be less reliable in routine practice than when used as a research tool. Inexplicable variations in serial measurements of breath hydrogen during clinical investigation in our hospital, prompted a series of studies, which have resulted in the identification of several factors, all capable of adversely influencing hydrogen measurement, and which therefore require careful control.

\section{Methods}

\section{HYPERVENTILATION}

Because exhaled breath hydrogen samples need to be collected as end-expiratory samples, repeated attempts at sample collection by untrained patients can cause hyperventilation. Patients unaccustomed to the hospital environment may also hyperventilate because of anxiety.

To test the influence of hyperventilation, seven healthy volunteers, accustomed to the collection technique provided serial samples, before and then, 
after 30 seconds mild hyperventilation.

A consistent reduction in the concentration of breath hydrogen was recorded immediately after hyperventilation (mean reduction 14 parts per million (ppm), standard deviation (SD 5), p $<0.01$ paired $t$ test, ${ }^{9}$ (Fig. 1). After resumption of a normal breathing pattern, hydrogen concentrations returned to baseline levels in all subjects.

\section{EXERCISE}

Breath hydrogen studies are often prolonged, and it is frequently difficult to restrain patients for their duration. To test whether exercise, by altering ventilation rate, could adversely influence breath hydrogen, five trained volunteers collected serial breath samples, before and after, a two minute period of slow, steady walking.

A consistent fall in breath hydrogen concentration was recorded immediately after walking, in all individuals, (Fig. 1), (mean reduction $10 \mathrm{ppm}, \mathrm{SD} 7$ $\mathrm{p}<0 \cdot 05)$.

\section{CIGARETTE SMOKING}

It has been suggested that cigarette smoke can interfere with gas chromatographic measurement of hydrogen. ${ }^{10}$ We therefore tested the influence of cigarette smoking on hydrogen measurements using the electrochemical cell. After 30 minutes abstinence from smoking, serial exhaled breath samples were collected from seven smokers before, during, and after, the smoking of a cigarette.

A rapid rise in the recorded values of hydrogen concentration was seen within the first five minutes

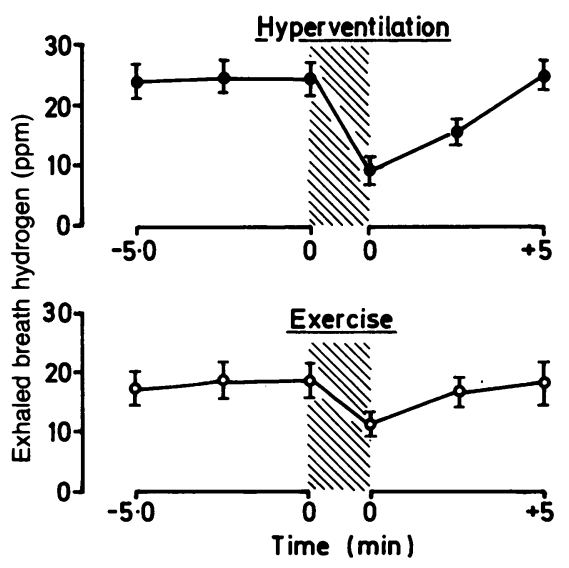

Fig. 1 Shows exhaled breath hydrogen concentrations (mean $\pm S E M)$, recorded from subjects before and after hyperventilation (top graph) or exercise (bottom graph). Recorded values show a consistent fall after both activities $(p<0 \cdot 01)$. of smoking (mean rise $70 \mathrm{ppm}, \mathrm{SD} 48, \mathrm{p}<0.01$ ) which then returned to basal levels after smoking ceased (Fig. 2).

Because the hydrogen sensitive electrochemical cell is also partially responsive to carbon monoxide (CO), $\left(100 \mathrm{ppm} \mathrm{CO}=8 \mathrm{ppm} \mathrm{H}_{2}\right)^{11}$ the smoking studies were repeated in five subjects, measuring in addition to the hydrogen, the CO concentration in each sample using a carbon monoxide monitor (GMI Ltd, Renfrew, Scotland). All subjects showed a rise in exhaled breath $\mathrm{CO}$ during smoking (mean rise $15.3 \mathrm{ppm}$; SD $5.6 \mathrm{p}<0.01$ ). The magnitude of this $\mathrm{CO}$ rise, however, indicated that $\mathrm{CO}$ could have accounted for only a small part of the change recorded on the hydrogen monitor.

\section{ORAL ANAEROBIC BACTERIA}

The colon is not the only region of the normal human gastrointestinal tract which harbours anaerobic bacteria. The mouth and pharynx are also colonised by anaerobes capable of carbohydrate fermentation. ${ }^{12}$ Thus, carbohydrate - for example, sucrose containing confectionery, placed in the mouth during the course of a breath hydrogen study could be fermented in the oropharynx and might generate hydrogen in sufficient quantity to interfere with data interpretation.

After an overnight fast and abstinence from morning tooth brushing, eight volunteers collected serial basal breath hydrogen samples, followed by a two minute mouth rinse with a $20 \%$ sucrose solution. Collections then continued at five minute intervals for a further 30 minutes. (Fig. 3).

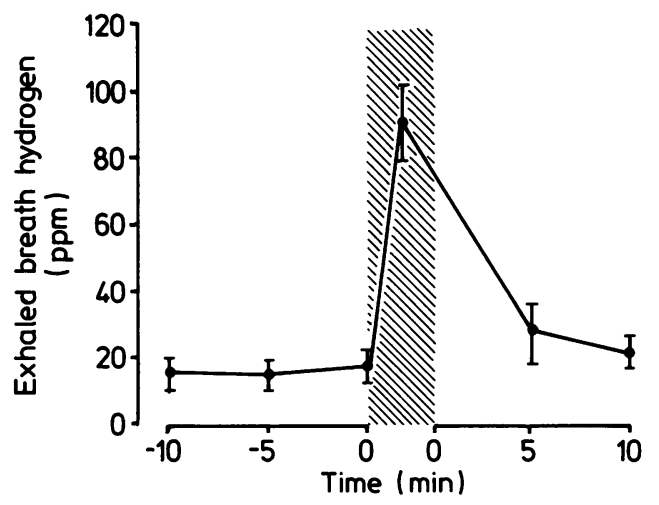

Fig. 2 Shows serial exhaled breath hydrogen concentrations (mean $\pm S E M$ ) from seven subjects during, and after, smoking (hatched bar). A marked rise in recorded values occurred during smoking $(p<0.01$ vs mean basal values). 


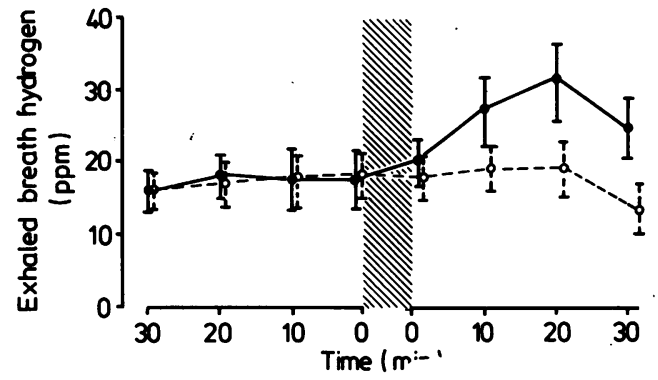

Fig. 3 This diagram shows serial exhaled breath hydrogen data (mean $\pm S E M)$ from seven subjects before, and after, $20 \%$ sucrose mouthwash (hatched bar). The continuous line shows a rise in breath hydrogen after sucrose $(p<0.05 \mathrm{vs}$ basal values). The dotted line shows the results of the repeat experiment in which oral hygiene (tooth brushing and $1 \%$ chlorhexidine), preceded the sucrose and attenuated the rise ( $p>0.1$ vs basal values).

In all subjects, a rise in breath hydrogen occurred (mean rise, $10 \mathrm{ppm}$, SD $10 \mathrm{p}<0.05$ ). Each subject then repeated the experiment on a second day, this time the sucrose rinse followed careful tooth brushing and a mouthwash with $1 \%$ chlorhexidine solution. This procedure attenuated the postsucrose breath hydrogen rise in each individual (mean rise: $2 \mathrm{ppm}$, SD $3 \mathrm{p}>0 \cdot 1$ ).

\section{Discussion}

Because the technique of exhaled breath hydrogen monitoring is non-invasive, simple, and inexpensive, it has major advantages over traditional methods for the investigation of suspected upper intestinal bacterial overgrowth, carbohydrate intolerance, or disordered transit. Our studies show, however, that the quality of information provided by the technique may be adversely influenced by several extraintestinal factors, all of which are capable of impairing test interpretation.

Hyperventilation, however induced, significantly reduces the concentration of exhaled breath hydrogen by 'washing out' hydrogen from the lungs. This source of error is easily eliminated by training patients in the technique of breath collection before the study, and by ensuring that sample collection is delayed until at least five minutes after any exercise.

Many gases are produced by tobacco combustion including methane (to which the electrochemical cell is insensitive) ${ }^{11}$ carbon monoxide (to which it is partially sensitive), and hydrogen (which occurs in a concentration of up to $2 \%$ ). ${ }^{13}$ It is therefore no surprise that cigarette smoke interferes profoundly with exhaled breath hydrogen measurements and it follows that smoking should cease well before studies begin and should be avoided throughout their duration.

Hydrogen production by the oropharyngeal microflora also adversely influences data interpretation, so it seems prudent to prohibit carbohydrate consumption during studies, especially sucrose containing confectionery or beverages. Furthermore, because oral anaerobes could also generate hydrogen from the test meal itself, careful oral hygiene should probably be carried out before starting any study. This is important when investigating patients with suspected upper intestinal bacterial overgrowth as an early rise in breath hydrogen might simulate the condition under investigation.

In conclusion, it seems sensible that breath hydrogen studies are done on relaxed, trained, non-smoking patients. Prior bactericidal mouthwash and the avoidance of unnecessary carbohydrate ingestion would further improve reliability.

The authors wish to thank Miss Hilary Clark for secretarial help and Dr D L Wingate for his advice in preparation of the manuscript. $D G T$ is a Wellcome Trust Senior Lecturer in Medicine. P B, $\mathrm{A} \mathrm{DeB}, \mathrm{S} \mathrm{W}$, and $\mathrm{M}$ W participated in this project during a BSc degree course in physiology, supported by the M R C.

\section{References}

1 Calloway DH, Colasito DJ, Mathews RD. Gases produced by human intestinal microflora. Nature 1966; 212: 1238-9.

2 Levitt MD. Production and excretion of hydrogen gas in man. $N$ Engl J Med 1969; 281: 122-7.

3 Metz G, Jenkins DJA, Peters TJ, Newman A, Blendis LM. Breath hydrogen as a diagnostic method for hypolactasia. Lancet 1975; 1: 1155-7.

4 Perman JA, Barr RG, Watkins JB. Sucrose malabsorption in children: noninvasive diagnosis by interval breath hydrogen determination. J Pediatr 1978; 93: 17-22.

5 Rhodes JM, Middleton P, Jewell DP. The lactulose hydrogen breath test as a diagnostic test for smallbowel bacterial overgrowth. Scand J Gastroenterol 1979; 14: 333-6.

6 Cann PA, Read NW, Brown C, Hobson N, Holdsworth $\mathrm{CD}$. Irritable bowel syndrome: relationship of disorders in the transit of a single meal to symptom patterns. Gut 1983; 24: 405-11.

7 Bergman I, Coleman JE, Evans D. A simple gas chromatograph with an electrochemical detector for the measurement of hydrogen and carbon monoxide in the parts per million range, applied to exhaled air. Chromatographia 1975; 8: 581-3. 
8 Corbett CL, Thomas S, Read NW, Hobson N, Bergman I, Holdsworth CD. Electrochemical detector for breath hydrogen determination: measurement of smallbowel transit time in normal subjects and patients with the irritable bowel syndrome. Gut 1981; 22: 836-40.

9 Armtage P. Statistical methods in medical research. Oxford: Blackwell, 1977.

10 Tadesse K, Eastwood M. Breath hydrogen test and smoking. Lancet 1977; 2: 91.
11 Manufacturers specifications, Renfrew, Scotland. GMI Ltd.

12 Hardie JM, Bowden GH. The normal microbial flora of the mouth. In: Skinner FA, Carr JG, eds. The normal microbical flora of man. New York: Academic Press, 1974.

13 Keith CH, Tesh PG. Measurement of the total smoke issuing from a burning cigarette. Tobacco Science 1965; 9: $61-4$. 